\title{
A biosurfactant-producing yeast Rhodotorula sp.CC01 utilizing landfill leachate as nitrogen source and its broad degradation spectra of petroleum hydrocarbons
}

\section{Xiaoyun Lin}

Ocean College, Zhejiang University

Hanghai Zhou

Ocean College,Zhejiang University

\section{Feng Zeng}

College of Environmental Science and Engineering, Guilin University of Technology, Guilin 541006, China

\section{Lijia Jiang}

Ocean College, Zhejiang University

\section{Edidiong Okokon Atakpa}

Ocean College, Zhejiang University

Chunfang Zhang ( $\nabla$ zhangcf@zju.edu.cn )

Zhejiang University https://orcid.org/0000-0003-1329-9630

\section{Qinglin Xie}

College of Environmental Science and Engineering, Guilin University of Technology, Guilin541006, China

\section{Research Article}

Keywords: Biosurfactant, Landfill leachate, Nitrogen source, Petroleum hydrocarbons, Rhodotorula sp

Posted Date: December 2nd, 2021

DOI: https://doi.org/10.21203/rs.3.rs-1070958/v1

License: (c) (1) This work is licensed under a Creative Commons Attribution 4.0 International License. Read Full License

Version of Record: A version of this preprint was published at World Journal of Microbiology and Biotechnology on March 5th, 2022. See the published version at https://doi.org/10.1007/s11274-02203254-z. 


\section{Abstract}

In this study, a biosurfactant producing strain, Rhodotorula sp. CC01 was isolated using landfill leachate as nitrogen source, while olive oil was determined as the best sole carbon source for producing biosurfactants. The biosurfactant produced by Rhodotorula sp. CC01 was characterized as glycolipids with a critical micelle concentration of $70 \mathrm{mg} / \mathrm{L}$, which showed stability over a wide range of $\mathrm{pH}(2-12)$, salinity $(0-100 \%)$, and temperature $\left(20-100^{\circ} \mathrm{C}\right)$. During the cultivation process, the surface tension decreased from 51.87 to $28.20 \mathrm{mN} / \mathrm{m}$ in $15 \mathrm{~h}$, and the removal efficiency of $\mathrm{NH}_{4}{ }^{+}-\mathrm{N}$ reached $84.2 \%$ after $75 \mathrm{~h}$ cultivation with a maximum $\mathrm{NH}_{4}{ }^{+} \mathrm{N}$ removal rate of $3.92 \mathrm{mg} \cdot \mathrm{L}^{-1} \cdot \mathrm{h}^{-1}$. In addition, Rhodotorula sp. CC01 has proven to be of great potential in remediating petroleum hydrocarbons, as revealed by chromogenic assays. The findings of this study prove a cost-effective strategy for the production of BS by yeast through the utilization of landfill leachate.

\section{Introduction}

Surfactants are amphiphilic compounds containing both hydrophilic and hydrophobic moieties (Ashitha et al., 2020; Markande et al., 2021; Sun et al., 2019). These moieties can reduce the surface and interfacial tensions and improve the solubility of hydrophobic compounds, thereby increasing the mobility and bioavailability of hydrophobic substrates (Ashitha et al., 2020; Derguine-Mecheri et al., 2021; Junhui Zhang, 2018). Surfactants can be synthesized by chemical routes, such as synthetic chemical surfactants, or produced by microorganisms, which are surface-active metabolites known as biosurfactant (BS) (Ahmed M. Eldin, 2019). Chemical surfactants tend to cause secondary pollution in soil and water, and pose potential hazards to human health and the environment (Derguine-Mecheri et al., 2021). Compared with chemical surfactants, BSs have more advantages, such as renewability, low toxicity, high biodegradability, and high environmental compatibility (Femina Carolin et al., 2021; Nogueira Felix et al., 2019; Rufino et al., 2011). In fact, surface tension could be reduced at lower concentrations of BS, making them more effective than chemical surfactants (Carolin et al., 2021). Overall, biosurfactant is a promising alternative for chemical surfactants (Femina Carolin et al., 2021; Nogueira Felix et al., 2019).

A large number of microorganisms have been reported to be capable of producing BS (Markande et al., 2021), such as Sphingobacterium (Burgos-Diaz et al., 2011), Bacillus (Sharma \& Pandey, 2020), Pseudomonas (Sun et al., 2019), Paracoccus (Xu et al., 2020), Acinetobacter (Zhou et al., 2020), and Wickerhamomyces anomalus (Teixeira Souza et al., 2018). Due to the high production cost, complicated purification process, and low yield, the mass production of BS is limited (Carolin et al., 2021). A large proportion of BS production cost comes from raw materials, and it is a good strategy to produce BS using waste resources instead of traditional raw materials, which can significantly reduce production costs (Dobler et al., 2020). Microorganisms require suitable carbon and nitrogen sources which are essential for the production and synthesis of BS. (Aparna et al., 2012; Datta et al., 2018; He et al., 2020; Rosas-Galvan et al., 2018). To achieve this, various carbon sources such as molasses, whey, glycerol, orange peelings, 
coconut oil cake, wastewater from olive oil mills, and crude glycerin were explored. (Aparna et al., 2012; Derguine-Mecheri et al., 2021; Dobler et al., 2020). Meanwhile, desirable nitrogen sources such as residual brewery yeast and urea were also explored for BS production. (Fonseca et al., 2007). However, few studies have worked on reducing the production cost of BS by replacing traditional nitrogen sources with $\mathrm{NH}_{4}{ }^{+} \mathrm{N}$ rich wastewaters, such as landfill leachate.

Landfill leachate is a type of wastewater comprised of rainwater, snow water, and moisture seepage from garbage landfills (Wu et al., 2016). Because of the complex composition, high organic matter and $\mathrm{NH}_{4}{ }^{+} \mathrm{N}$ concentrations, landfill leachate poses great threats to ecosystems, including surrounding soils, rivers, groundwater, and the ocean environment (Koc-Jurczyk \& Jurczyk, 2017; Ren et al., 2017; Wu et al., 2020; Yuan et al., 2019). On the other hand, compared with chemical and physical methods, biological treatment is a better choice for landfill leachate treatments due to the cost-effectiveness, environmental friendliness and feasibility (Yu et al., 2014; Zhang et al., 2020). However, high concentrations of $\mathrm{NH}_{4}{ }^{+}-\mathrm{N}$ in landfill leachate leads to poor biodegradability and low $\mathrm{C} / \mathrm{N}$ ratio and presents a great challenge to biological methods (Yu et al., 2014). Owing to the aforementioned problems, the removal of $\mathrm{NH}_{4}{ }^{+}-\mathrm{N}$ from landfill leachate is necessary. Currently, $\mathrm{NH}_{4}{ }^{+} \mathrm{N}$ pretreatment strategies mainly include nitrogen blowing, coagulation, electrocoagulation, oxidation, photocatalysis, and so on (Pirsaheb et al., 2015; Wang et al., 2003; Yu et al., 2014). However, most of these treatments are cost-consuming and can potentially cause secondary pollution (Yu et al., 2014). Using landfill leachate as a nitrogen source to produce BS can be a promising alternative to alleviate the nitrogen pollution.

Besides the landfill leachate problem, many petroleum hydrocarbons leakage occurs every year (Priya et al., 2015). Improper treatments threaten the environment through soil, groundwater, and ocean pollution (Sood \& Lal, 2009). Biodegradation is a potentially powerful remediation approach to decontaminate oil pollutants since petroleum hydrocarbons occur naturally in the environment, and numerous microorganisms possess ability to utilize them as carbon sources and energy for growth (Yang et al., 2020). To date, studies on the application of biosurfactant-producing microorganisms to oil pollution have been extensively reported (Wei et al., 2020; Yang et al., 2020). However, few studies have reported the application of BS produced by Rhodotorula in these processes.

Hence, the main objectives of this study were to: 1) isolate BS-producing yeast using landfill leachate as nitrogen source and characterize the properties of the corresponding biosurfactants produced; 2 ) investigate the effect of the strain on nitrogen removal in landfill leachate; and 3) explore the effect of the strain on petroleum hydrocarbon utilization. This study is the first attempt to produce biosurfactants using landfill leachate as the nitrogen source. This could provide insightful information for the development of nitrogen removal strategy from landfill leachate.

\section{Materials And Methods}

Isolation of BS-producing strain 
The landfill leachate used for the isolation of BS-producing strain was collected from Tuan Jishan Island of Zhoushan, China ( $122^{\circ} 6 \mathrm{C}^{4} 4$ "N, $29^{\circ} 58^{\prime} 15$ "E). About $1 \mathrm{~mL}$ of landfill leachate was added into $200 \mathrm{~mL}$ of mineral salt medium (MSM) supplemented with $1 \%$ olive oil. The composition of MSM (pH 6.5-7.0) was the same as previously reported (Zhou et al., 2015). The culture was incubated at $30^{\circ} \mathrm{C}$ with shaking (180 rpm) for 3 days. Then, the culture suspension was scribed in blood agar plate (Ohadi et al., 2017) and blue agar plate (Sun et al., 2019), and incubated overnight. The isolates, which formed halos around their colonies, were incubated in the MSM with $1 \%$ olive oil as the sole carbon source. Ultimately, the culture supernatants were collected to evaluate the oil spreading performance and surface tension (ST). Briefly, $200 \mathrm{~mL}$ distilled water was poured in a petri plate $(20 \mathrm{~cm})$, followed by the addition of $400 \mu \mathrm{L}$ crude oil to the surface of the water (Huang et al., 2020a). Then, $10 \mu \mathrm{L}$ of cell-free supernatant was added to the center of the oil film, the MSM without inoculum was used as a control. The diameter of the clear zone was measured immediately. For ST measurement, $10 \mathrm{ml}$ of the supernatant was taken in a petri dish and analyzed using a tension-meter (BZY 201, Shanghai Fangrui Instrument Co.Ltd, China) at room temperature.

Molecular identification of the isolated yeast

The strain with the best performance was selected for molecular identification. The genomic DNA was obtained using a EasyPure ${ }^{\circledR}$ Genomic DNA Kit (purchased from TransGen Biotech). The extracted DNA was further subjected to polymerase chain reaction (PCR) with ITS rRNA universal primers of ITS1 (TCCGTAGGTGAACCTGCGG) and ITS4 (TCCTCCGCTTATTGATATGC). The DNA sequence was compared with that of other microorganisms by BLAST. A phylogenetic tree was constructed using MEGA 7.0 software via the neighbour-joining method (Huang et al., 2020a).

Optimization of BS-producing conditions

Eight carbon sources were individually added to MSM ( $1 \% \mathrm{v} / \mathrm{v})$ as the sole carbon source, including yeast extract, sodium acetate, glucose, $n$-hexadecane, olive oil, glycerol, diesel oil and paraffin. After 3 days of incubation $\left(30^{\circ} \mathrm{C}, 180 \mathrm{rpm}\right)$, the cell-free supernatant was collected by centrifugation at $8000 \mathrm{rpm}$ for 5 min, then further characterized through ST and growth $\left(\mathrm{OD}_{600} \mathrm{~nm}\right)$ evaluations.

Growth and nitrogen removal performance of Rhodotorula sp.CC01

The Rhodotorula sp.CC01 activated overnight in yeast extract peptone dextrose medium was inoculated into the fermentation medium $(1 \%, \mathrm{v} / \mathrm{v})$, and cultured at $30^{\circ} \mathrm{C}$ and $180 \mathrm{rpm}$. The compositions of fermentation medium ( $\mathrm{pH}$ 6.5-7.0) were as follows (g/L): $\mathrm{NaCl}, 15 ; \mathrm{KH}_{2} \mathrm{PO}_{4}, 0.5, \mathrm{~K}_{2} \mathrm{HPO}_{4}, 1 ; \mathrm{MgSO}_{4}, 0.5$; $\mathrm{KCl}, 0.01$; olive oil, $10 ; 10 \mathrm{~mL}$ of landfill leachate and $1 \mathrm{~mL}$ of trace elements (Zhou et al., 2015). Growth $\left(\mathrm{OD}_{600} \mathrm{~nm}\right), \mathrm{ST}, \mathrm{NH}_{4}{ }^{+}-\mathrm{N}, \mathrm{NO}_{2}{ }^{-}-\mathrm{N}$ and $\mathrm{NO}_{3}{ }^{-}-\mathrm{N}$ concentrations of the culture were measured at intervals to evaluate the growth potential and nitrogen removal performance. The concentrations of $\mathrm{NH}_{4}{ }^{+}-\mathrm{N}, \mathrm{NO}_{2}{ }^{-}-\mathrm{N}$ and $\mathrm{NO}_{3}{ }^{-} \mathrm{N}$ were determined via a fully automatic chemical analyzer (Cleverchem380G, DeChem-Tech. $\mathrm{GmbH}$, Germany) after filtration through $0.22 \mu \mathrm{m}$ pore size nylon filters (Bkmam, Changde, China). 
The BS extraction was performed according to the methods previously described by Zhou et al. (Zhou et al., 2020). Briefly, the culture broth was centrifuged at $8500 \mathrm{rpm}$ for $5 \mathrm{~min}$ to obtain cell-free supernatant. Thereafter, $200 \mathrm{~mL}$ ethyl acetate was added to the precipitate. Subsequently, the organic phase was separated and concentrated by evaporation in the rotary vacuum evaporator to obtain the crude BS. For drop-collapse test, $1 \mathrm{ml}$ of the culture supernatant was dyed with $100 \mu \mathrm{l}$ of $0.003 \%$ methylene blue solution, and $50 \mu \mathrm{l}$ of the mixture was dropped onto parafilm. After $1 \mathrm{~min}$, the droplet collapse was observed. MSM medium was used as a control. For CMC determination, the BS was dissolved in distilled water at concentrations ranging from $20 \mathrm{mg} / \mathrm{L}$ to $200 \mathrm{mg} / \mathrm{L}$. ST was measured at each concentration until a constant value was reached. CMC was determined by plotting ST as a function of the BS concentration. For stability analysis of BS, the BS solution of $100 \mathrm{mg} / \mathrm{L}$ was treated at different temperatures (i.e., $20,40,60,80$, and $100^{\circ} \mathrm{C}$ ), salinity (i.e., $0,20,40,60,80$, and $100 \mathrm{~g} / \mathrm{L}$ ), $\mathrm{pH}$ (i.e., 2, 4, 6, 8 , 10 , and 12) and the ST measurements were repeated three times.

Structure analysis of the BS

The structural property of the BS was investigated through thin layer chromatography (TLC), fourier transform infrared spectrum (FTIR), and gas chromatography-mass spectrometry (GC-MS) analysis. For TLC analysis, BS was dissolved in petroleum ether, and then absorbed by capillary tube. About $2 \mu \mathrm{L}$ of solution was spotted on the silica gel plate (Merck, Darmstadt, Germany). The mobile phase of the petroleum ether/ethyl acetate $(2: 1, \mathrm{v} / \mathrm{v})$ was used to separate the compounds. lodine, $10 \%$ phosphomolybdic acid solution, $0.25 \%$ ninhydrin solution, and phenol-ammonium sulfate, was used to detect lipids, phospholipid, peptide, and carbohydrate, respectively. FTIR (IS10, Thermo-Nicolet, America) was used to analyze the surfactant in the spectral region of $4000 \mathrm{~cm}^{-1}-400 \mathrm{~cm}^{-1}$ to detect the characteristic functional groups in the sample. The composition and structure of fatty acids in BS were analyzed by GCMS according to the methods as previously reported (Zhou et al., 2020).

2,6-dichlorophenolindophenol (2,6-DCPIP) test

The Rhodotorula sp.CC01 cultured overnight was centrifuged and resuspended with $0.9 \%$ saline solution to remove the medium components. Substrates used in the experiment are as follows: cyclooctane, $n$ decane, $n$-hexadecane, octadecane, phenanthrene, light crude oil, heavy crude oil, and liquid paraffin. Prepare aqueous solution by dissolving Octadecane and phenanthrene in petroleum ether respectively. The reaction mixture contained approximately $750 \mu \mathrm{L}$ MSM medium, $200 \mu \mathrm{L}$ 2,6-DCPIP solution (37.5 $\mathrm{mg} / \mathrm{L}), 50 \mu \mathrm{L} \mathrm{FeCl}_{3} \cdot 6 \mathrm{H}_{2} \mathrm{O}$ solution $(150 \mathrm{mg} / \mathrm{L}), 200 \mu \mathrm{L}$ cell suspension, and $10 \mu \mathrm{L}$ sterilized substrate. The reaction was performed in an incubator $\left(30^{\circ} \mathrm{C}, 180 \mathrm{rpm}\right)$ for $72 \mathrm{~h}$ to observe the color change.

Statistical analyses and calculations

The $\mathrm{NH}_{4}{ }^{+}-\mathrm{N}, \mathrm{NO}_{2}{ }^{-}-\mathrm{N}$ and inorganic $\mathrm{TN}$ removal ratios were calculated as follows: $\left(\mathrm{c}_{0}-\mathrm{c}_{1}\right) / \mathrm{c}_{0} \times 100 \%$, where $\mathrm{c}_{0}$ is the initial $\mathrm{NH}_{4}{ }^{+}-\mathrm{N} / \mathrm{NO}_{2}{ }^{-}-\mathrm{N} /$ inorganic TN concentration and $\mathrm{c}_{1}$ is the final concentration 
(Wang et al., 2021; Zeng et al., 2020). The sum of $\mathrm{NH}_{4}{ }^{+}-\mathrm{N}$ and $\mathrm{NO}_{3}{ }^{+}-\mathrm{N}, \mathrm{NO}_{2}{ }^{-}-\mathrm{N}$ was defined as inorganic TN (Lu et al., 2019). The data generated in this study were analysed using Microsoft Excel and SPSS 13.0. Graphs were prepared using Origin 9.1.

\section{Results}

Isolation and identification of BS-producing strains

As shown in Table 1, four strains with BS-producing ability were isolated. Among them, the BS produced by the yeast strain $\mathrm{CC} 01$ showed the best performance. The CC01 supernatant exhibited the largest oil displacement diameter and the lowest ST (Table 1). Generally, the larger the oil spreading diameters, the better the activity of BS (Zhou et al., 2020). The efficiency of the yeast strain CC01 for the production of BS was confirmed by the reduction in ST (from 71.99 to $34.77 \mathrm{mN} \cdot \mathrm{m}^{-1}$ ), a flattened drop, as well as spread oil positive with a displacement zone diameter of $19.9 \pm 0.1 \mathrm{~cm}$ (Table 1 \& Fig. 1b). Morphology of the yeast strain CC01 in LB agar plate was shown in Fig. 1b. The strain was identified as Rhodotorula sp, whose phylogenetic tree was constructed and presented in Fig. 1c. The ITS rRNA gene sequence of CC01 has been submitted to GenBank with an accession number MZ950605.

Table 1

Characterization of the isolated strains with BS-producing ability

\begin{tabular}{|lll|}
\hline Isolates & Oil displacement diameters $(\mathrm{cm})$ & $\mathbf{S T}(\mathrm{mN} / \mathrm{m})$ \\
\hline CС06 & $1.00 \pm 0.50$ & $51.85 \pm 0.44$ \\
CC04 & $2.50 \pm 1.00$ & $50.34 \pm 0.20$ \\
\hline CC01 & $19.90 \pm 0.10$ & $34.77 \pm 0.63$ \\
\hline СВ02 & $1.95 \pm 0.65$ & $54.30 \pm 0.30$ \\
\hline
\end{tabular}

Effect of carbon sources on BS production

Biosurfactant production is affected by the culture medium, in which carbon, nitrogen and trace element sources are essential to promote production (Nazareth et al., 2021). Among the eight carbon substrates examined, olive oil $(1 \%, \mathrm{w} / \mathrm{v})$ exhibited the best performance, with the corresponding ST of the culture medium dropped to $27.66 \mathrm{mN} / \mathrm{m}$ (Fig. 2a). Meanwhile, the highest growth of Rhodotorula sp.CC01 was also observed with olive oil as carbon source, suggesting that the reduction in ST positively correlated with the cell growth (Fig. 2a).

Growth kinetics and BS production of Rhodotorula sp.CC01

After establishing the optimum carbon source for cultivation, the growth kinetics and BS production (demonstrated by surface tension) were analyzed. As evident from the results displayed, the adaptive phase of Rhodotorula sp.CC01 occurred in the first $39 \mathrm{~h}$, followed by the exponential phase prolonged 
until $123 \mathrm{~h}$ (Fig. 2b). Meanwhile, ST of the culture reduced from $51.87 \pm 1.74$ to $28.20 \pm 0.51 \mathrm{mN} / \mathrm{m}$ after $15 \mathrm{~h}$ of cultivation during the early exponential and remained stable throughout the incubation period of $243 \mathrm{~h}$.

Nitrogen removal performance of Rhodotorula sp.CC01

The landfill leachate used in this study is rich in nitrogen sources with ammonium concentration as high as $3000 \mathrm{mg} / \mathrm{L}$. Therefore, it was supplemented to the medium as nitrogen sources at the ratio of $1 \%$ (V/V) for the production of BS by Rhodotorula sp.CC01. The ability of Rhodotorula sp.CC01 to assimilate different nitrogen sources in the medium was further investigated. It could be observed that with the growth of the strain $\mathrm{CC} 01$, a decrease in $\mathrm{NH}_{4}{ }^{+} \mathrm{N}$ occurred immediately and $87.5 \%$ of $\mathrm{NH}_{4}{ }^{+}-\mathrm{N}$ was removed in $75 \mathrm{~h}$ and the maximum $\mathrm{NH}_{4}{ }^{+} \mathrm{N}$ removal rate was $3.92 \mathrm{mg} \cdot \mathrm{L}^{-1} \cdot \mathrm{h}^{-1}$ (Fig. 3a). Similarly, while $\mathrm{NH}_{4}{ }^{+}-\mathrm{N}$ was rapidly removed, the removal efficiency of $\mathrm{NO}_{2}{ }^{-}-\mathrm{N}$ reached $71.7 \%$ (Fig. 3b). In addition, it is worth noting that significant fluctuations in $\mathrm{NO}_{3}{ }^{-}-\mathrm{N}$ were observed during the process (Fig. 3c), which is probably attributed to heterotrophic nitrification. Finally, the removal efficiency of inorganic TN reached $80.6 \%$ after $75 \mathrm{~h}$ cultivation, and strain CC01 proliferated without a lag phase (Fig. 3d), suggesting that nitrogen might be mainly assimilated to organic matter (Civiero et al., 2018).

\section{Properties of produced BS}

In this study, the CMC of the BS produced by Rhodotorula sp.CC01 was $70 \mathrm{mg} / \mathrm{L}$ and the ST was 33.39 $\mathrm{mN} / \mathrm{m}$ (Fig. 4a). Meanwhile, the BS exhibited stable surface activity under different $\mathrm{pH}$ conditions (Fig. 4b). Similarly, the ST of BS had no significant change with salinity ranging from 0 to $100 \mathrm{mg} / \mathrm{L}$ (Fig. 4c). In addition, the BS also showed excellent stability over a wide temperature range (Fig. 4d).

TLC analysis showed that the BS produced by Rhodotorula sp.CC01 is completely separated using different solvent systems and shows three points $\left(R_{f 1}=0.18, R_{f 2}=0.70, R_{f 3}=0.87\right)$ (Fig. 6a). Further chromogenic reaction analysis revealed that the BS contained lipids, peptides, and sugar compounds (Fig. 5a-c), demonstrating that it would be categorized as glycolipoprotein.

FTIR analysis revealed that BS and standard rhamnolipid were fairly similar (Fig. 5d). The primary difference observed in BS and standard rhamnolipid was the bands of $3371 \mathrm{~cm}^{-1}$ (O-H stretch) (Sen et al., 2017). The bands observed at wavenumber $2923 \mathrm{~cm}^{-1}$ and $2853 \mathrm{~cm}^{-1}$ were attributed to the characteristic $\mathrm{C}-\mathrm{H}$ stretching and vibration, indicating the existence of methyl and methylene groups, respectively (Ashitha et al., 2020; Liu et al., 2014) (Fig. 5d). The peak at $1745 \mathrm{~cm}^{-1}$ corresponded to $\mathrm{C}=0$ stretching of lactones and the absorption bands at $1464 \mathrm{~cm}^{-1}$ were caused by $\mathrm{C}-\mathrm{H}$ stretching and vibration of fatty acid group (Ashitha et al., 2020; Burgos-Diaz et al., 2011; Xiao et al., 2013). The absorption bands observed at $1161 \mathrm{~cm}^{-1}$ demonstrated the existence of $\mathrm{C}-\mathrm{O}$ and $\mathrm{C}-\mathrm{O}-\mathrm{C}$ bonds of the carboxylic acids, and the bands at $1377 \mathrm{~cm}^{-1}$ revealed the presence of $\mathrm{C}-\mathrm{N}$ bonds (Derguine-Mecheri et al., 2021; Sen et al., 2017). Above all, FTIR result revealed the presence of aliphatic chains and peptide moieties. 
The BS of Rhodotorula sp.CC01 after methyl esterification and hydrolysis was analyzed by GC-MS in order to identify the fatty acid types (Ashitha et al., 2020). Four peaks were observed through GC-MS analysis, which were close to methyl hexadecanoate (C16:0), methyl octadecanoate (C18:0), methyl octadecanoate (C18:1), and methyl octadecanoate (C18:2) (Fig. 5e).

Petroleum hydrocarbon utilization range by Rhodotorula sp.CC01

It could be observed that the color of the reaction group containing cyclooctane as the sole carbon source became colorless. This is also the case for other sole carbon sources such as $n$-decane, $n$-hexadecane, octacosane, phenanthrene, light crude oil, heavy crude oil, and paraffin, respectively (Fig. 6). Meanwhile, colors of control groups remained blue (Fig. 6). Thus, it could be considered that Rhodotorula sp.CC01 had a wide utilization range of petroleum hydrocarbon including short chain alkanes, medium chain alkanes, long chain alkanes, mixed crude oil, PAHs, and liquid paraffin.

\section{Discussion}

In this work, innovative approaches have been developed and applied as strategies to valorize landfill leachate as a nitrogen source for low-cost biosurfactant production by the yeast Rhodotorula sp.CC01. The carbon source of the culture medium was optimized and the olive oil showed better performance. A previous study also reported the promotion of BSs production by microorganisms cultivated in medium containing olive oil (Huang et al., 2020b). Meanwhile, Teixeira et al.(2018) evaluated BS production by Wickerhamomyces anomalus CCMA 0358 yeast and clarified olive oil as an essential carbon source. Derguine et al. (2021) also investigated BS production by Rhodotorula sp.YBR using olive oil mill wastewater as substrate for low-cost production, and the produced BSs showed good surface activity with a yield of $10.08 \pm 0.38 \mathrm{~g} \mathrm{~L}^{-1}$.

Incubation experiment showed that ST reduction was observed after $15 \mathrm{~h}$ when growth occurred at the adaptive phase, indicating that the strain can efficiently utilize olive oil and landfill leachate to produce BS in a short time (Fig. 2b). The biomass increased with incubation time and reached a maximum at 147 $h$, whereas the ST remained steady till the end of the cultivation period. Similar growth-associated production of BS was also observed by Suparna et al. (2017). However, Santos et al. (2017) reported that the highest reduction in ST due to BS production by Streptomyces sp. DPUA 1559 was observed after 60 $\mathrm{h}$ during the stationary growth.

The results of nitrogen removal analysis showed that the removal efficiency of $\mathrm{NH}_{4}{ }^{+} \mathrm{N}$ was $87.5 \%$ and the maximum $\mathrm{NH}_{4}{ }^{+} \mathrm{N}$ removal rate was $3.92 \mathrm{mg} \cdot \mathrm{L}^{-1} \cdot \mathrm{h}^{-1}$, which was significantly higher than that of Acinetobacter tandoii MZ-5 (2.28 mg. $\mathrm{L}^{-1} \cdot \mathrm{h}^{-1}$ ) (Ouyang et al., 2020), Pseudomonas tolaasii Y-11(2.04 $\mathrm{mg} \cdot \mathrm{L}^{-1} \cdot \mathrm{h}^{-1}$ ) (He et al., 2016), and Bacillus methylotrophicus $\mathrm{L} 7\left(2.15 \mathrm{mg} \cdot \mathrm{L}^{-1} \cdot \mathrm{h}^{-1}\right.$ ) (Zhang et al., 2012). Similarly, while $\mathrm{NH}_{4}{ }^{+}-\mathrm{N}$ was rapidly removed, the accumulation of $\mathrm{NO}_{3}{ }^{-} \mathrm{N}$ was observed for the red yeast Sporidiobolus pararoseus $\mathrm{Y} 1$ while $\mathrm{NO}_{2}{ }^{-}-\mathrm{N}$ accumulation was not evident (Zeng et al., 2020). 
Generally, reducing ST (below $35 \mathrm{mN} / \mathrm{m}$ ) is one of the critical indicators for selecting BS-producing microorganisms (Chandankere et al., 2014). Thus, the CMC of the BS in this study was compared with that produced by other yeasts and bacteria reported in literature (Table 2). The results showed that the BS produced by Rhodotorula sp.CC01 had much lower CMC than others, indicating higher aggregation ability and better surface activity (Aparna et al., 2012; Derguine-Mecheri et al., 2021; Huang et al., 2020b; Luna et al., 2013; Sen et al., 2017).

Table 2

Comparision of BS produced by different strains

\begin{tabular}{|c|c|c|c|c|}
\hline Strain & $\mathrm{CMC}(\mathrm{mg} / \mathrm{L})$ & $\mathrm{ST}(\mathrm{mN} / \mathrm{m})$ & Types of BS & Reference \\
\hline $\begin{array}{l}\text { Pseudomonas } \\
\text { sp. 2B }\end{array}$ & 100 & 29.73 & Glycolipids & (Aparna et al., 2012) \\
\hline $\begin{array}{l}\text { Serratia } \\
\text { marcescensZCF25 }\end{array}$ & 220 & 29.50 & lipopeptide & (Huang et al., 2020b) \\
\hline Rhodotorula sp. YBR & 180 & 30.16 & Glycolipids & $\begin{array}{l}\text { (Derguine-Mecheri et al., } \\
\text { 2021) }\end{array}$ \\
\hline $\begin{array}{l}\text { Rhodotorula babjevae } \\
\text { YS3 }\end{array}$ & 130 & 35 & $\begin{array}{l}\text { Sophorae } \\
\text { lipid }\end{array}$ & (Sen et al., 2017) \\
\hline $\begin{array}{l}\text { Candida sphaerica } \\
\text { UCP0995 }\end{array}$ & 250 & 25 & Glycolipids & (Luna et al., 2013) \\
\hline Rhodotorula sp.CCO1 & 70 & 33.39 & Glycolipids & This study \\
\hline
\end{tabular}

The BS produced by the yeast Rhodotorula sp.CC01 was classified as glycolipoprotein by TLC. Similarly, Derguine et al. reported that the BS produced by Rhodotorula sp. YBR was characterized as glycolipoprotein, including carbohydrate $\left(R_{f}=0.62\right)$, protein $\left(R_{f}=0.48\right)$ and lipid $\left(R_{f}=0.76\right)$ (DerguineMecheri et al., 2021). The type of the BS produced by Rhodotorula babjevaeYS3 was determined as sophorolipid (Sen et al., 2017). Further FTIR analysis showed that the BS produced by the strain CC01 exhibited similar functional groups with standard rhamnolipid, which are in agreement with those obtained with TLC. Moreover, the BS of Rhodotorula sp.CC01 was mainly hexadecanoic acid and octadecenoic acid by GC-MS analysis.

\section{Conclusion}

This study reported the isolation and identification of an indigenous BS-producing yeast strain from landfill leachate. The strain Rhodotorula sp.CC01 produced BS using landfill leachate as its nitrogen source, and the removal efficiency of $\mathrm{NH}_{4}{ }^{+}-\mathrm{N}$ was $84.2 \%$ after $75 \mathrm{~h}$ cultivation. The strain opens new future prospects for BS produced at lower costs as an alternative to chemical surfactants and nitrogen 
removal from landfill leachate. Meanwhile, Rhodotorula sp.CC01 exhibits a broad utilization spectrum of petroleum hydrocarbons, suggesting a promising prospect in the remediation of petroleum hydrocarbon pollutants.

\section{Declarations}

\section{CRediT authorship contribution statement}

Xiaoyun Lin: Conceptualization, Methodology, Investigation, Formal analysis, Data curation, Writing original draft; Hanghai Zhou: Investigation, Formal analysis, Data curation; Feng Zeng: Investigation; Lijia Jiang: Investigation; Edidiong Okokon Atakpa: Manuscript revision; Chunfang Zhang: Validation, Writing review \& editing, Project administration; Qinglin Xie: Review \& editing.

\section{Declarations of interest}

The authors declare that they have no known competing financial interests or personal relationships that could have appeared to influence the work reported in this paper.

\section{Acknowledgements}

This study was financially supported by the National Natural Science Foundation of China (51978189; 52070050), the Zhoushan Science and Technology Department Project (2019C81056), and by the Research Funds of the Guangxi Key Laboratory of Theory and technology for Environmental Pollution Control (No.2001K004).

\section{References}

1. Ahmed M, Eldin ZK, Nermeen, Hossam (2019) Isolation and genetic identification of yeast producing biosurfactants, evaluated by different screening methods. Microchem J 146:309-314

2. Aparna A, Srinikethan G, Smitha H (2012) Production and characterization of biosurfactant produced by a novel Pseudomonas sp. 2B. Colloids Surf B Biointerfaces 95:23-29

3. Ashitha A, Mathew EKR, J (2020) Characterization of biosurfactant produced by the endophyte Burkholderia sp. WYAT7 and evaluation of its antibacterial and antibiofilm potentials. J Biotechnol 313:1-10

4. Burgos-Diaz C, Pons R, Espuny MJ, Aranda FJ, Teruel JA, Manresa A, Ortiz A, Marques AM (2011) Isolation and partial characterization of a biosurfactant mixture produced by Sphingobacterium $\mathrm{sp}$. isolated from soil. J Colloid Interface Sci 361(1):195-204

5. Carolin CF, Kumar PS, Ngueagni PT (2021) A review on new aspects of lipopeptide biosurfactant: Types, production, properties and its application in the bioremediation process. J Hazard Mater 407:124827 
6. Chandankere R, Yao J, Cai M, Masakorala K, Jain AK, Choi MMF (2014) Properties and characterization of biosurfactant in crude oil biodegradation by bacterium Bacillus methylotrophicus USTBa. Fuel 122:140-148

7. Civiero E, Pintus M, Ruggeri C, Tamburini E, Sollai F, Sanjust E, Zucca P (2018) Physiological and Phylogenetic Characterization of Rhodotorula diobovata DSBCA06, a Nitrophilous Yeast.Biology (Basel), 7(3)

8. Datta P, Tiwari P, Pandey LM (2018) Isolation and characterization of biosurfactant producing and oil degrading Bacillus subtilis MG495086 from formation water of Assam oil reservoir and its suitability for enhanced oil recovery. Bioresour Technol 270:439-448

9. Derguine-Mecheri L, Kebbouche-Gana S, Djenane D (2021) Biosurfactant production from newly isolated Rhodotorula sp.YBR and its great potential in enhanced removal of hydrocarbons from contaminated soils. World J Microbiol Biotechnol 37(1):18

10. Dobler L, Ferraz HC, Araujo de Castilho LV, Sangenito LS, Pasqualino IP, Souza Dos Santos AL, Neves BC, Oliveira RR, Freire G, Almeida DM, R.V (2020) Environmentally friendly rhamnolipid production for petroleum remediation. Chemosphere 252:126349

11. Femina Carolin C, Kumar PS, Joshiba GJ, Madhesh P, Ramamurthy R (2021) Sustainable strategy for the enhancement of hazardous aromatic amine degradation using lipopeptide biosurfactant isolated from Brevibacterium casei. J Hazard Mater 408:124943

12. Fonseca RR, Silva AJR, De França FP, Cardoso VL, Sérvulo EFC (2007) Optimizing carbon/nitrogen ratio for biosurfactant production by a Bacillus subtilis strain. Appl Biochem Biotechnol 137(1):471486

13. He S, Ni Y, Lu L, Chai Q, Yu T, Shen Z, Yang C (2020) Simultaneous degradation of n-hexane and production of biosurfactants by Pseudomonas sp. strain NEE2 isolated from oil-contaminated soils. Chemosphere 242:125237

14. He T, Li Z, Sun Q, Xu Y, Ye Q (2016) Heterotrophic nitrification and aerobic denitrification by Pseudomonas tolaasii Y-11 without nitrite accumulation during nitrogen conversion. Bioresour Technol 200:493-9

15. Huang X, Zhou H, Ni Q, Dai C, Chen C, Li Y, Zhang C (2020a) Biosurfactant-facilitated biodegradation of hydrophobic organic compounds in hydraulic fracturing flowback wastewater: A dose-effect analysis. Environmental Technology \& Innovation, 19

16. Huang Y, Zhou H, Zheng G, Li Y, Xie Q, You S, Zhang C (2020b) Isolation and characterization of biosurfactant-producing Serratia marcescens ZCF25 from oil sludge and application to bioremediation. Environ Sci Pollut Res Int 27(22):27762-27772

17. Zhang J, Hui HL, Gao S Hu, Quanhong Xue (2018) Prevention and mitigation of paraffin deposition by biosurfactant-producing and paraffin-degrading Bacillus amyloliquefaciens strain 6-2c. Chem Eng J 335:510-519

18. Koc-Jurczyk J, Jurczyk L (2017) Biological Treatment of Landfill Leachate at Elevated Temperature in the Presence of Polyurethane Foam of Various Porosity. Clean-Soil Air Water, 45(3) 
19. Liu H, Wang H, Chen X, Liu N, Bao SJEM, Assessment (2014) Biosurfactant-producing strains in enhancing solubilization and biodegradation of petroleum hydrocarbons in groundwater. 186:458145897

20. Lu LL, Wang BJ, Zhang Y, Xia LJ, An D, Li HJ (2019) Identification and nitrogen removal characteristics of Thauera sp. FDN-01 and application in sequencing batch biofilm reactor. Sci Total Environ 690:61-69

21. Luna JM, Rufino RD, Sarubbo LA, Campos-Takaki GM (2013) Characterisation, surface properties and biological activity of a biosurfactant produced from industrial waste by Candida sphaerica UCP0995 for application in the petroleum industry. Colloids Surf B Biointerfaces 102:202-209

22. Markande AR, Patel D, Varjani S (2021) A review on biosurfactants: properties, applications and current developments. Bioresour Technol 330:124963

23. Nazareth TC, Zanutto CP, Maass D, de Souza AAU, de Souza S, M.d.A (2021) Bioconversion of lowcost brewery waste to biosurfactant: An improvement of surfactin production by culture medium optimization. Biochemical Engineering Journal, 172

24. Nogueira Felix AK, Martins JJL, Lima Almeida JG, Giro MEA, Cavalcante KF, Melo M, Pessoa VML, Rocha ODP, Barros MVR, Goncalves L, de Santiago Aguiar R (2019) Purification and characterization of a biosurfactant produced by Bacillus subtilis in cashew apple juice and its application in the remediation of oil-contaminated soil. Colloids Surf B Biointerfaces, 175, 256-263

25. Ohadi M, Dehghannoudeh G, Shakibaie M, Banat IM, Pournamdari M, Forootanfar H (2017) Isolation, characterization, and optimization of biosurfactant production by an oil-degrading Acinetobacter junii B6 isolated from an Iranian oil excavation site. Biocatal Agric Biotechnol 12:1-9

26. Ouyang L, Wang K, Liu X, Wong MH, Hu Z, Chen H, Yang X, Li S (2020) A study on the nitrogen removal efficacy of bacterium Acinetobacter tandoii MZ-5 from a contaminated river of Shenzhen, Guangdong Province, China. Bioresour Technol 315:123888

27. Pirsaheb M, Azizi E, Almasi A, Soltanian M, Khosravi T, Ghayebzadeh M, Sharafi K (2015) Evaluating the efficiency of electrochemical process in removing COD and NH4-N from landfill leachate. Desalination Water Treat 57(15):6644-6651

28. Priya A, Mandal AK, Ball AS, Manefield M, Lal B, Sarma PM (2015) Mass culture strategy for bacterial yeast co-culture for degradation of petroleum hydrocarbons in marine environment. Mar Pollut Bull 100(1):191-199

29. Ren Y, Ferraz F, Kang AJ, Yuan Q (2017) Treatment of old landfill leachate with high ammonium content using aerobic granular sludge. J Biol Eng 11:42

30. Rosas-Galvan NS, Martinez-Morales F, Marquina-Bahena S, Tinoco-Valencia R, Serrano-Carreon L, Bertrand B, Leon-Rodriguez R, Guzman-Aparicio J, Alvarez-Berber L, Trejo-Hernandez MR (2018) Improved production, purification, and characterization of biosurfactants produced by Serratia marcescens SM3 and its isogenic SMRG-5 strain. Biotechnol Appl Biochem 65(5):690-700

31. Rufino RD, Luna JM, Sarubbo LA, Rodrigues LR, Teixeira JA, Campos-Takaki GM (2011) Antimicrobial and anti-adhesive potential of a biosurfactant Rufisan produced by Candida lipolytica 
UCP 0988. Colloids Surf B Biointerfaces 84(1):1-5

32. Santos APP, Silva MDS, Costa EVL, Rufino RD, Santos VA, Ramos CS, Sarubbo LA, Porto ALF (2017) Production and characterization of a biosurfactant produced by Streptomyces sp. DPUA 1559 isolated from lichens of the Amazon region. Braz J Med Biol Res 51(2):e6657

33. Sen S, Borah SN, Bora A, Deka S (2017) Production, characterization, and antifungal activity of a biosurfactant produced by Rhodotorula babjevae YS3. Microb Cell Fact 16(1):95

34. Sharma S, Pandey LM (2020) Production of biosurfactant by Bacillus subtilis RSL-2 isolated from sludge and biosurfactant mediated degradation of oil. Bioresour Technol 307:123261

35. Sood N, Lal B (2009) Isolation of a novel yeast strain Candida digboiensis TERI ASN6 capable of degrading petroleum hydrocarbons in acidic conditions. J Environ Manage 90(5):1728-1736

36. Sun S, Wang Y, Zang T, Wei J, Wu H, Wei C, Qiu G, Li F (2019) A biosurfactant-producing Pseudomonas aeruginosa S5 isolated from coking wastewater and its application for bioremediation of polycyclic aromatic hydrocarbons. Bioresour Technol 281:421-428

37. Teixeira Souza KS, Gudina EJ, Schwan RF, Rodrigues LR, Dias DR, Teixeira JA (2018) Improvement of biosurfactant production by Wickerhamomyces anomalus CCMA 0358 and its potential application in bioremediation. J Hazard Mater 346:152-158

38. Wang F, Smith DW, El-Din MG (2003) Application of advanced oxidation methods for landfill leachate treatment - A review. J Environ Eng Sci 2(6):413-427

39. Wang R, Xu Q, Chen C, Li X, Zhang C, Zhang D (2021) Microbial nitrogen removal in synthetic aquaculture wastewater by fixed-bed baffled reactors packed with different biofilm carrier materials. Bioresour Technol 331:125045

40. Wei Z, Wang JJ, Meng Y, Li J, Gaston LA, Fultz LM, DeLaune RD (2020) Potential use of biochar and rhamnolipid biosurfactant for remediation of crude oil-contaminated coastal wetland soil: Ecotoxicity assessment. Chemosphere 253:126617

41. Wu C, Chen W, Gu Z, Li Q (2020) A review of the characteristics of Fenton and ozonation systems in landfill leachate treatment.Sci Total Environ,143131

42. Wu L, Zhang LY, Xu YY, Liang CZ, Kong H, Shi X, Peng YZ (2016) Advanced nitrogen removal using bio-refractory organics as carbon source for biological treatment of landfill leachate. Sep Purif Technol 170:306-313

43. Xiao B, Yang D-y, Shi R-j, Zhang Y, Zhang Y, Hao J-s, Li G-q, Zhao J-y (2013) Screening of an efficient biosurfactant-producing bacterial strain and the structure and property of its surface-active metabolic product. Shengtaixue Zazhi 32(3):779-786

44. Xu M, Fu X, Gao Y, Duan L, Xu C, Sun W, Li Y, Meng X, Xiao X (2020) Characterization of a biosurfactant-producing bacteria isolated from Marine environment: Surface activity, chemical characterization and biodegradation. Journal of Environmental Chemical Engineering, 8(5)

45. Yang Z, Hollebone BP, Shah K, Yang C, Brown CE, Dodard S, Sarrazin M, Sunahara G (2020) Biodegradation potential assessment by using autochthonous microorganisms from the sediments from Lac Megantic (Quebec, Canada) contaminated with light residual oil. Chemosphere 239:124796 
46. Yu D, Yang J, Teng F, Feng L, Fang X, Ren H (2014) Bioaugmentation treatment of mature landfill leachate by new isolated ammonia nitrogen and humic acid resistant microorganism. $J$ Microbiol Biotechnol 24(7):987-997

47. Yuan CL, Lu CH, Ma YG, Wang YZ, Xie YH, Zhang K, Wang YQ, Lv LT, Feng XL, Zhu T (2019) A novel method to treat old landfill leachate combining multi-stage biological contact oxidation (MBCO) and single-stage autotrophic nitrogen removal using anammox and partial nitrification (SNAP). Chem Eng J 359:1635-1643

48. Zeng J, Liao S, Qiu M, Chen M, Ye J, Zeng J, Wang A (2020) Effects of carbon sources on the removal of ammonium, nitrite and nitrate nitrogen by the red yeast Sporidiobolus pararoseus $Y 1$. Bioresour Technol 312:123593

49. Zhang F, Li X, Wang Z, Jiang H, Ren S, Peng Y (2020) Simultaneous Ammonium oxidation denitrifying $(S A D)$ in an innovative three-stage process for energy-efficient mature landfill leachate treatment with external sludge reduction. Water Res 169:115156

50. Zhang QL, Liu Y, Ai GM, Miao LL, Zheng HY, Liu ZP (2012) The characteristics of a novel heterotrophic nitrification-aerobic denitrification bacterium, Bacillus methylotrophicus strain L7. Bioresour Technol 108:35-44

51. Zhou H, Chen J, Yang Z, Qin B, Li Y, Kong X (2015) Biosurfactant production and characterization of Bacillus sp. ZG0427 isolated from oil-contaminated soil. Ann Microbiol 65(4):2255-2264

52. Zhou H, Huang X, Liang Y, Li Y, Xie Q, Zhang C, You S (2020) Enhanced bioremediation of hydraulic fracturing flowback and produced water using an indigenous biosurfactant-producing bacteria Acinetobacter sp. Y2.Chemical Engineering Journal, 397

\section{Figures}



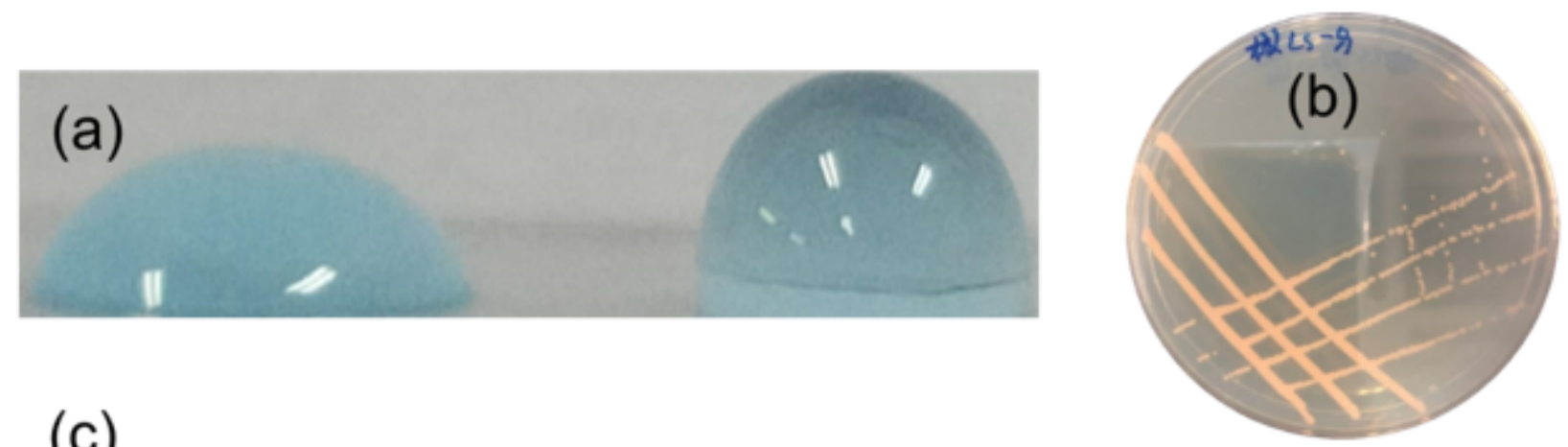

(c)

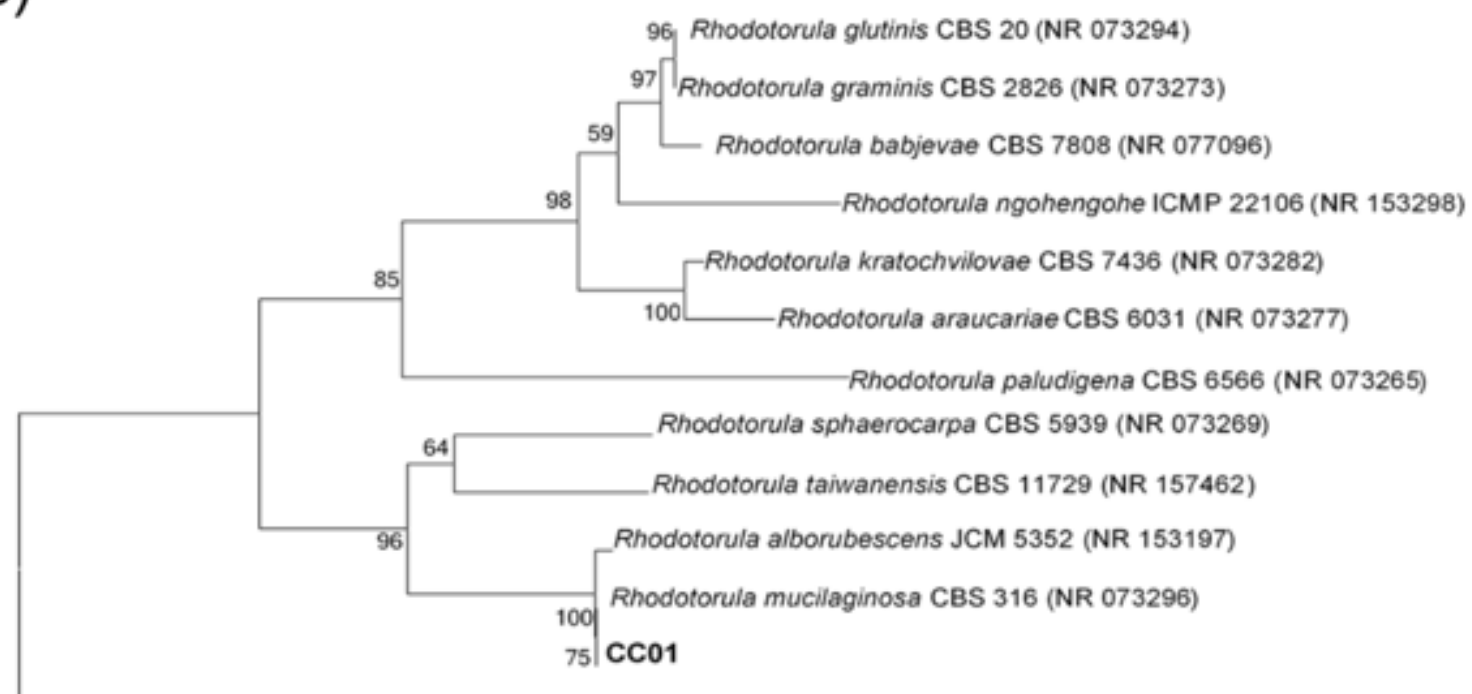

Rhodosporidiobolus ruineniae CBS 5001 (NR 155707)

\section{Figure 1}

Drop-collapse test (a), morphological characteristics under plate (b), phylogenetic relationship (c) of strain CC01 isolated from landfill leachate. In Fig. a, right image represents control while left image represents cell-free supernatant. In Fig. $c$, the tree is constructed using ITS rDNA gene sequence using neighbour-joining method. 
(a)
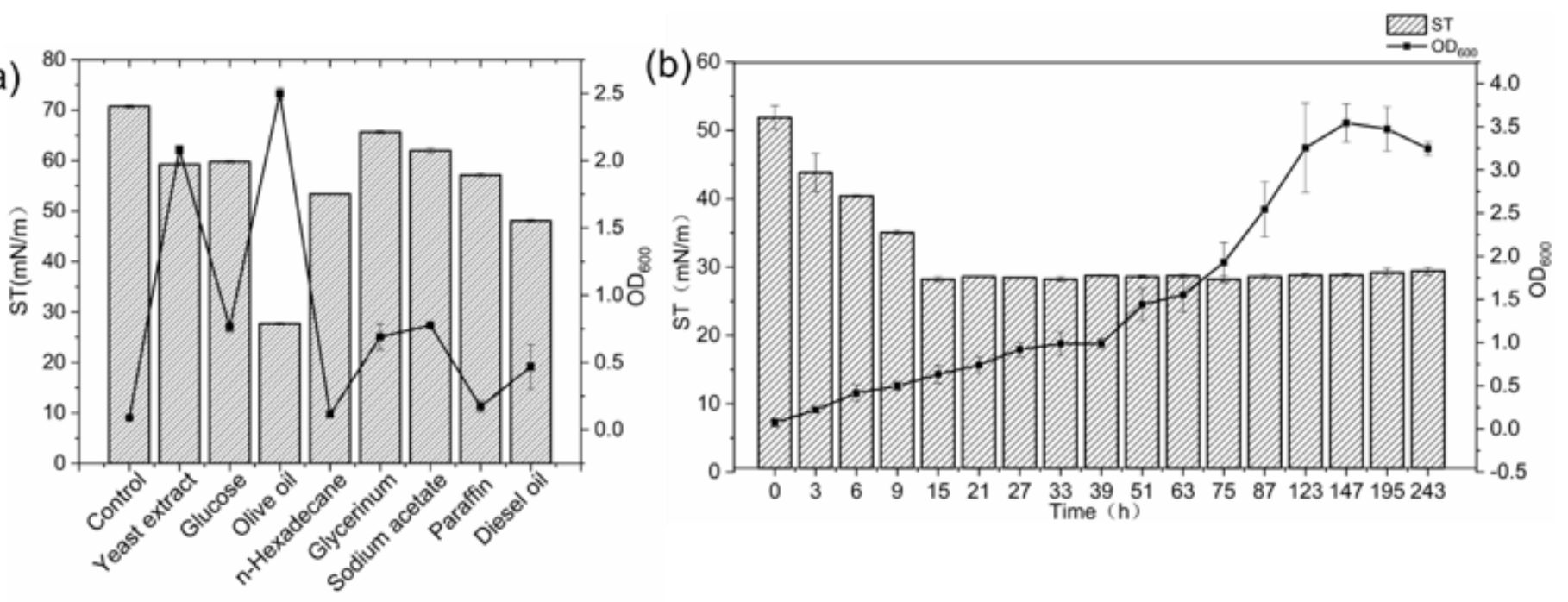

Figure 2

(a) Effects of eight carbon sources on ST and OD600 of strain CC01 after 72 hours of incubation. (b) Kinetics of growth and ST of strain CC01 during 243 hours of incubation. The error bars represent the standard deviations.

(a)

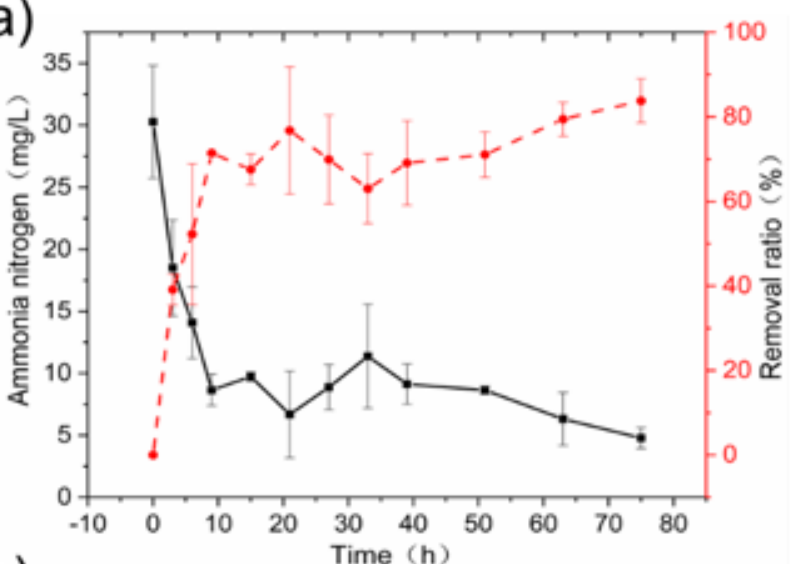

(c)

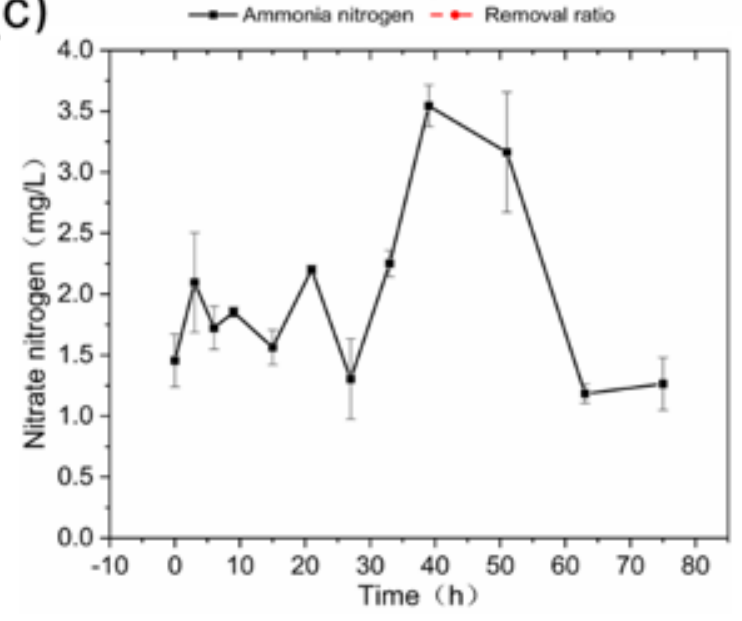

(b)

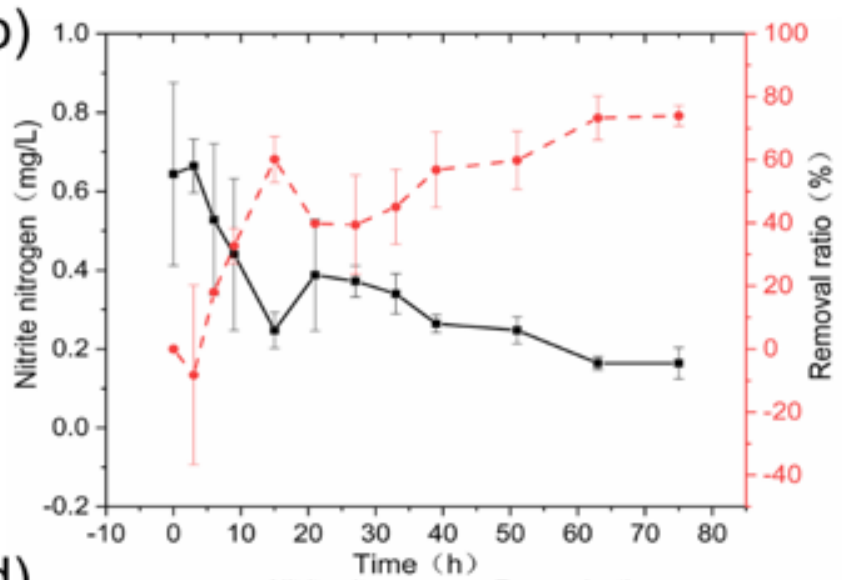

(d)

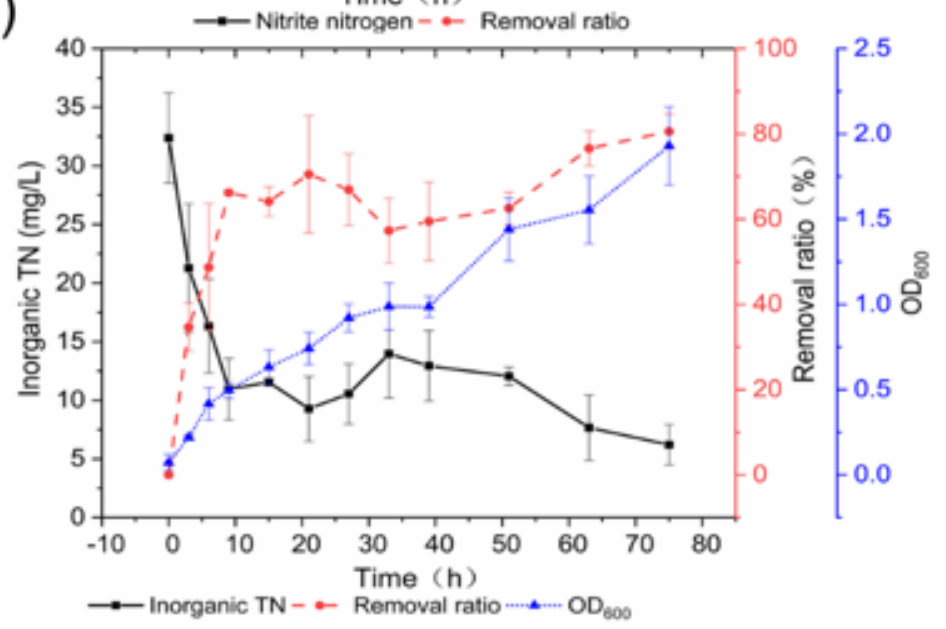

Figure 3 
The removal performance of NH4+-N (a), NO2-N (b), NO3--N (c) and inorganic TN (d) in landfill leachate by strain $\mathrm{CC} 01$ during $75 \mathrm{~h}$ cultivation. The error bars represent the standard deviations.
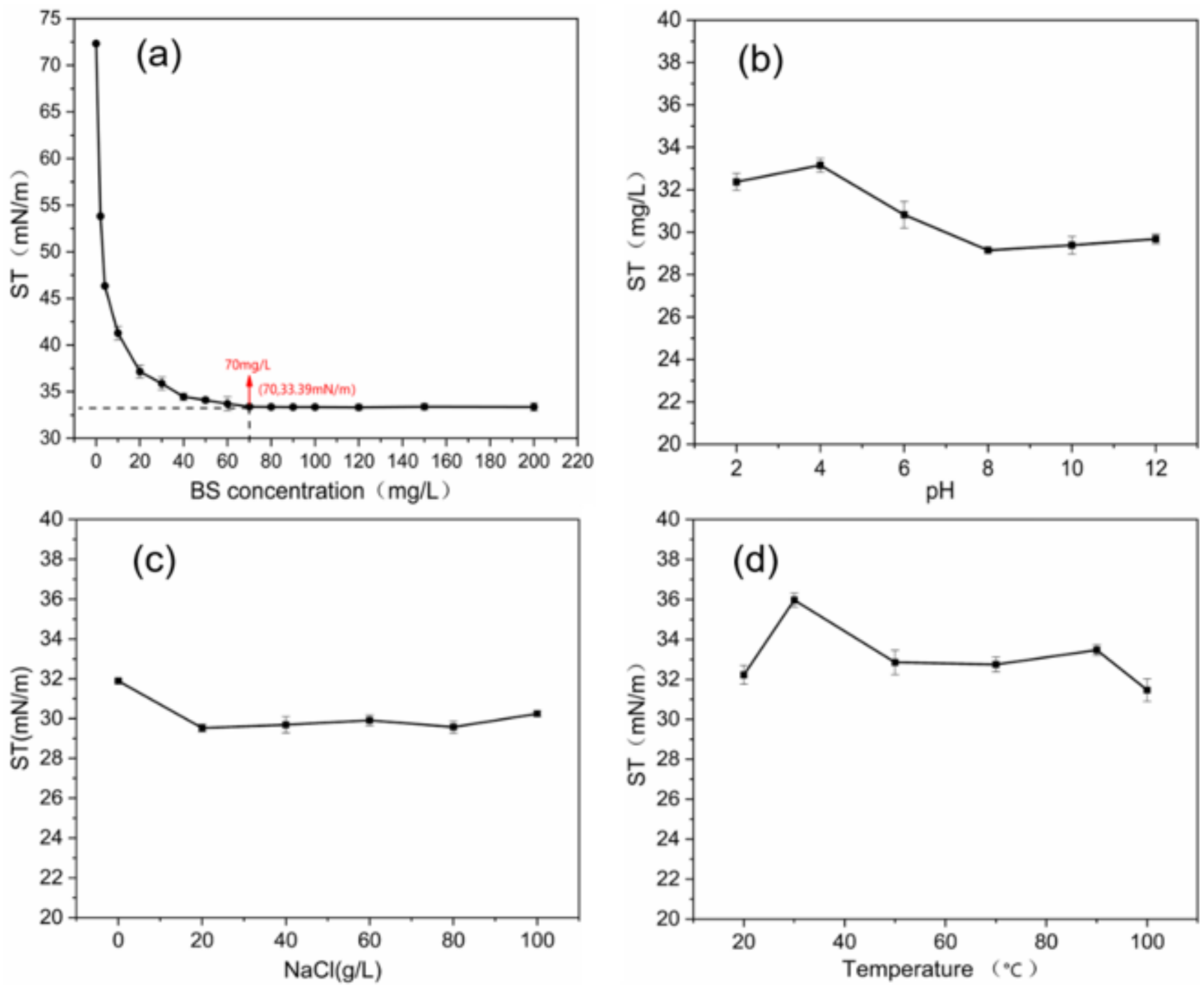

Figure 4

The CMC determination of the BS produced by strain CCO1 (a); The BS stability against different pH (b), salinity (c), and temperature (d). The error bars represent the standard deviations. 

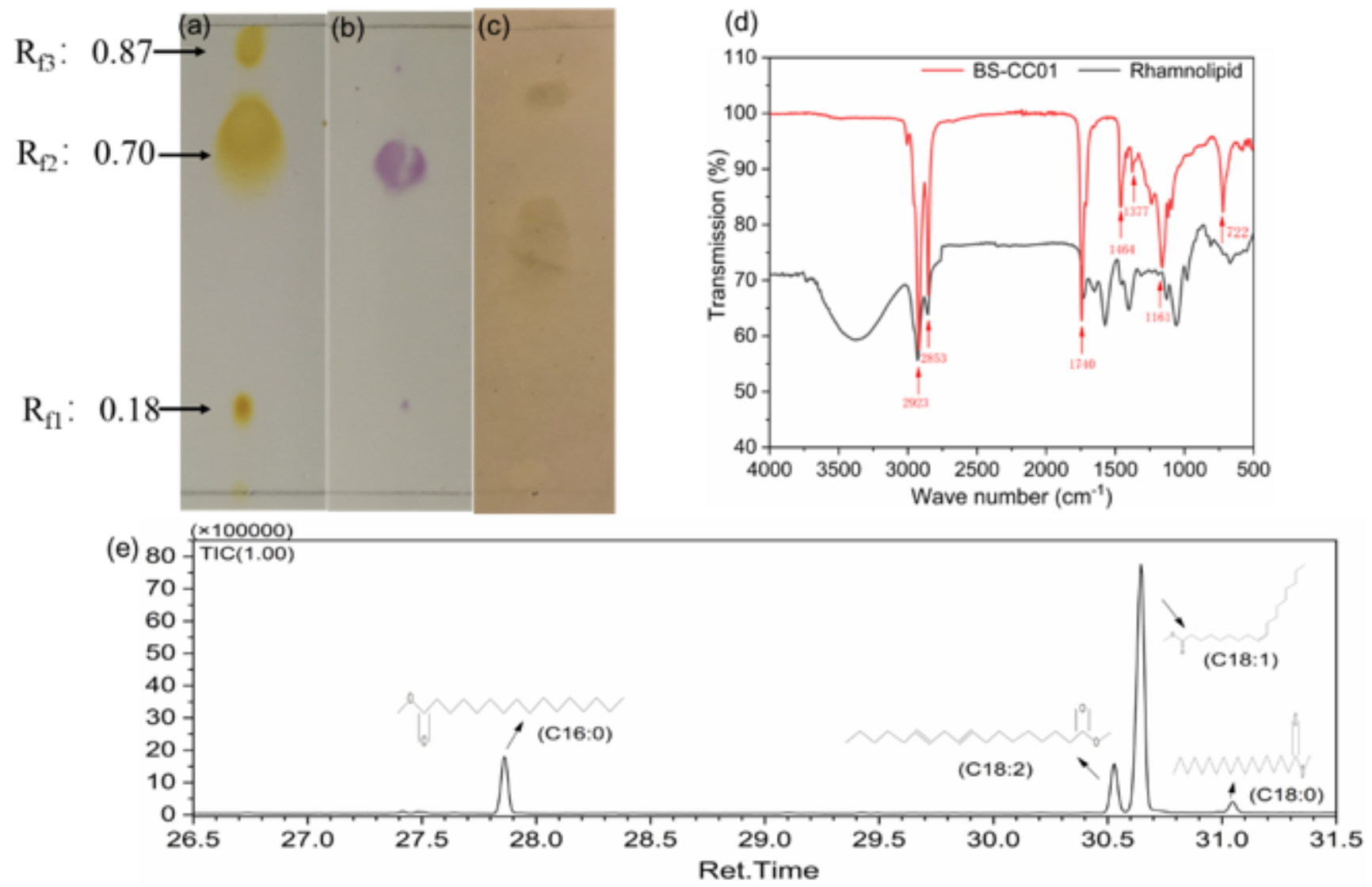

\section{Figure 5}

TLC (a-c), FTIR spectra (d), and GC-MS (e) analysis of the BS produced by strain CC01. In Fig. a-c, a image represented iodine vapours of color detection. The citric yellow is positive. $B$ image represented the color detection spraying ninhydrin solution to detect peptide content. $\mathrm{C}$ image represented the color detection spraying sulfuric acid phenol solution to detect sugar compounds. 


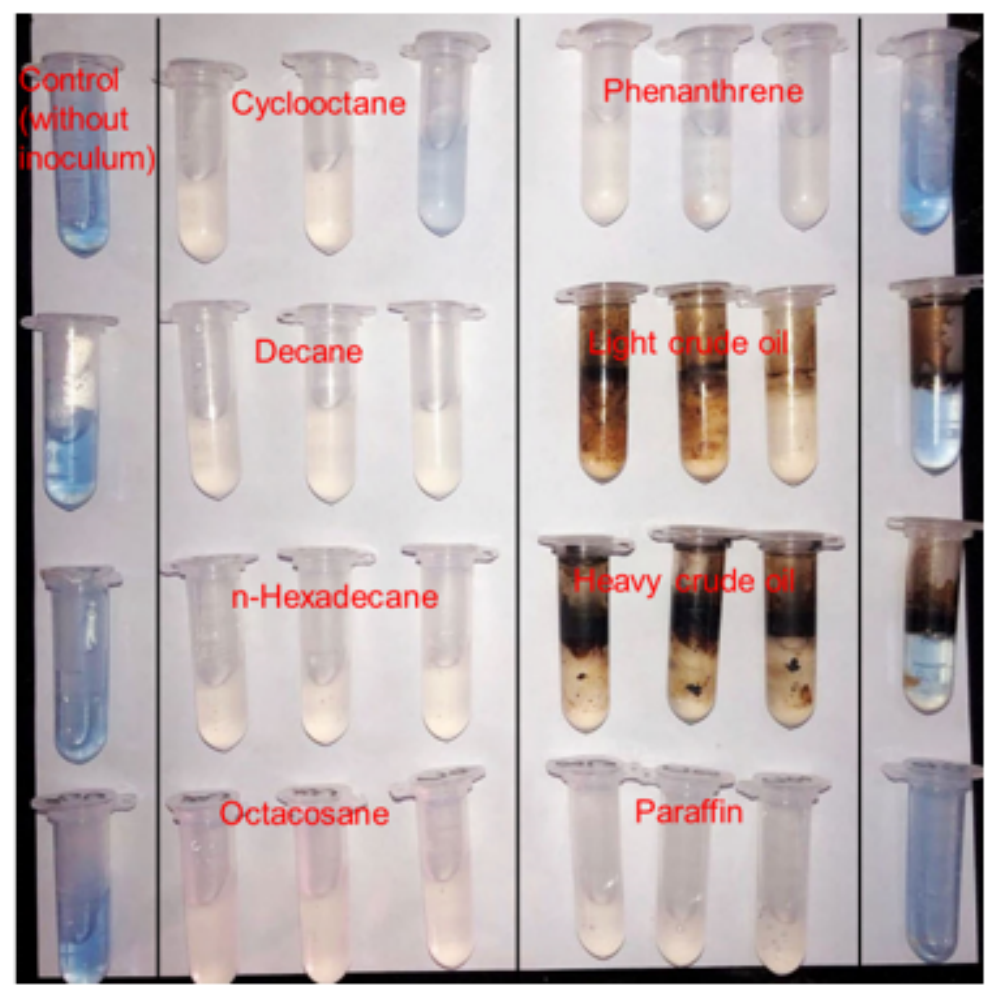

Figure 6

2,6-DCPIP experimental results of strain CC01

\section{Supplementary Files}

This is a list of supplementary files associated with this preprint. Click to download.

- GraphicalAbstract20211104.docx 